\title{
Magnetic interactions in the Martensitic phase of Mn rich Ni-Mn-In shape memory alloys
}

\author{
D. N. Lobo, ${ }^{1}$ Sandhya Dwivedi, ${ }^{2}$ C. A. daSilva, ${ }^{3}$ N. O. Moreno, ${ }^{3}$ K. R. Priolkar,, , and A. K. Nigam ${ }^{2}$ \\ ${ }^{1}$ Department of Physics, Goa University, Taleigao Plateau, Goa 403206 India \\ ${ }^{2}$ Tata Institute of Fundamental Research, Dr. Homi Bhabha Road, Colaba, Mumbai 400005 India \\ ${ }^{3}$ Departamento de Fisica, Universidade Federal de Sergipe, São Cristóvão, SE, 49100-000, Brazil
}

(Dated: June 14, 2021)

\begin{abstract}
The magnetic properties of $\mathrm{Mn}_{2} \mathrm{Ni}_{(1+x)} \operatorname{In}_{(1-x)}(x=0.5,0.6,0.7)$ and $\mathrm{Mn}_{(2-y)} \mathrm{Ni}_{(1.6+y)} \operatorname{In}_{0.4}(y$ $=-0.08,-0.04,0.04,0.08)$ shape memory alloys have been studied. Magnetic interactions in the martensitic phase of these alloys are found to be quite similar to those in $\mathrm{Ni}_{2} \mathrm{Mn}_{(1+x)} \operatorname{In}_{(1-x)}$ type alloys. Doping of $\mathrm{Ni}$ for In not only induces martensitic instability in $\mathrm{Mn}_{2} \mathrm{NiIn}$ type alloys but also affects magnetic properties due to a site occupancy disorder. Excess Ni preferentially occupies X sites forcing $\mathrm{Mn}$ to the $\mathrm{Z}$ sites of $\mathrm{X}_{2} \mathrm{YZ}$ Heusler composition resulting in a transition from ferromagnetic ground state to a state dominated by ferromagnetic $\mathrm{Mn}(\mathrm{Y})$ - $\mathrm{Mn}(\mathrm{Y})$ and antiferromagnetic $\mathrm{Mn}(\mathrm{Y})$ $\mathrm{Mn}(\mathrm{Z})$ interactions. These changes in magnetic ground state manifest themselves in observation of exchange bias effect even in zero field cooled condition and virgin magnetization curve lying outside the hysteresis loop.
\end{abstract}

\section{INTRODUCTION}

Interest in ferromagnetic shape memory alloys (FSMAs) due to their technological potential have generated much attention in recent years $\frac{1-3}{\underline{3}}$. These alloys have the generic formula $\mathrm{X}_{2} \mathrm{YZ}$ where the $\mathrm{X}$ and $\mathrm{Y}$ atoms are $3 \mathrm{~d}$ elements while $\mathrm{Z}$ is a group IIIAVA element. They undergo a diffusionless transformation from high temperature austenitic cubic structure to low temperature (martensitic) tetragonal or orthorhombic structure ${ }^{3}$. One such system extensively studied is $\mathrm{Ni}_{2} \mathrm{MnGa}$ which undergoes martensitic transformation at $\mathrm{T}_{M} \sim 220 \mathrm{~K}$. Martensitic transformation can also be induced in $\mathrm{Z}=\mathrm{In}$, $\mathrm{Sn}$ or $\mathrm{Sb}$ but in off-stoichiometric compositions, $\mathrm{Ni}_{2} \mathrm{Mn}_{(1+x)} \mathrm{Z}_{(1-x)^{\frac{4}{4}}}$. Apart from the martensitic transformation these alloys exhibit other interesting properties like large magnetocaloric effects, magnetic superelasticity $\underline{\underline{4}-7}$ and magnetic field induced giant strains $\frac{8,9}{}$, exchange bias $\frac{10,11}{1}$ etc.

Alloys of the type $\mathrm{Mn}_{2} \mathrm{NiZ}$ have higher Mn content compared to the traditional $\mathrm{Ni}_{2} \mathrm{MnZ}$ and is considered beneficial in realizing better magnetic, magnetocaloric and magnetotransport properties $\stackrel{12-14}{2} . \mathrm{Mn}_{2} \mathrm{NiGa}$ is one such Mn rich alloy which undergoes martensitic transformation at $\mathrm{T}_{M} \sim 270 \mathrm{~K}$ in an ferrimagnetically ordered state $\left(\mathrm{T}_{C}=588 \mathrm{~K}\right)^{\underline{15}}$. Ferrimagnetic order has also been confirmed from band structure calculations and arise due to unequal magnetic moments of antiferromagnetically coupled $\mathrm{Mn}$ atoms occupying the $\mathrm{X}$ and $\mathrm{Y}$ sites of $\mathrm{X}_{2} \mathrm{YZ}$ Heusler structure $\underline{16-20}$. Although martensitic transformations have been theoretically predicted in other $\mathrm{Mn}_{2} \mathrm{NiZ}(\mathrm{Z}=\mathrm{In}, \mathrm{Sn}, \mathrm{Sb})$ alloys, experimental investigations have reported these alloys to have stable crystal structures ${ }^{21,22}$. However, just as in case of $\mathrm{Ni}_{2} \mathrm{MnZ}$ alloys wherein martensitic instability is caused by partial substitution of $\mathrm{Z}$ atoms by $\mathrm{Mn}$, increasing of $\mathrm{Ni}$ content at the expense of $\mathrm{Z}$ atoms in $\mathrm{Mn}_{2} \mathrm{NiZ}$ results in martensitic alloys 23,24 . However, realization of such al- loys with general composition $\mathrm{Mn}_{2} \mathrm{Ni}_{(1+x)} \mathrm{Z}_{(1-x)}$ can lead to a structural disorder due to site preferences of transition metal ions. In a L2 $2_{1}$ Heusler composition Ni atoms prefer X sites as compared to Z sites 25 and therefore doping excess $\mathrm{Ni}$ could result in newer magnetic interactions as it would force Mn to occupy the $\mathrm{Z}$ sites. These conditions can change the sign of RKKY interaction leading to magnetic frustration or a new type of magnetic order. Local structural disorder is shown to be primarily responsible for martensitic transformation and magnetic interactions in the martensitic state of $\mathrm{Ni}_{2} \mathrm{Mn}_{1+x} \mathrm{In}_{1-x}$ type alloys $26-28$. In case of $\mathrm{Mn}_{2} \mathrm{NiGa}$ as well, site occupancy disorder has been shown to be an important factor in explaining magnetic properties of the martensitic state $\underline{29}$. The antisite disorder is also shown to be responsible for the zero field cooled exchange bias in $\mathrm{Mn}_{2} \mathrm{PtGa}^{30}$.

In this paper we focus our attention on understanding the magnetic properties of $\mathrm{Mn}_{2} \mathrm{Ni}_{(1+x)} \mathrm{In}_{(1-x)}(x=0.5$, $0.6,0.7)$ and $\mathrm{Mn}_{(2-y)} \mathrm{Ni}_{(1.6+y)} \operatorname{In}_{0.4}(-0.08 \leq y \leq 0.08)$ type alloys especially in their martensitic state. By comparing the magnetic properties of martensitic and structurally stable alloys having nearly similar compositions, we show that low temperature magnetic properties of the martensitic alloys are dominated by ferromagnetic and antiferromagnetic interactions, arising due to site occupancy disorder in these Mn rich alloys.

\section{EXPERIMENTAL}

The samples of above composition were prepared by arc melting the weighed constituents in argon atmosphere followed by encapsulating in a evacuated quartz tube and annealing at $750 \mathrm{C}$ for 48 hours and subsequent quenching in ice cold water. The prepared alloys were cut in suitable sizes using a low speed diamond saw and part of the sample was powdered and re-annealed in the same procedure above. X-ray diffraction (XRD) patterns were 


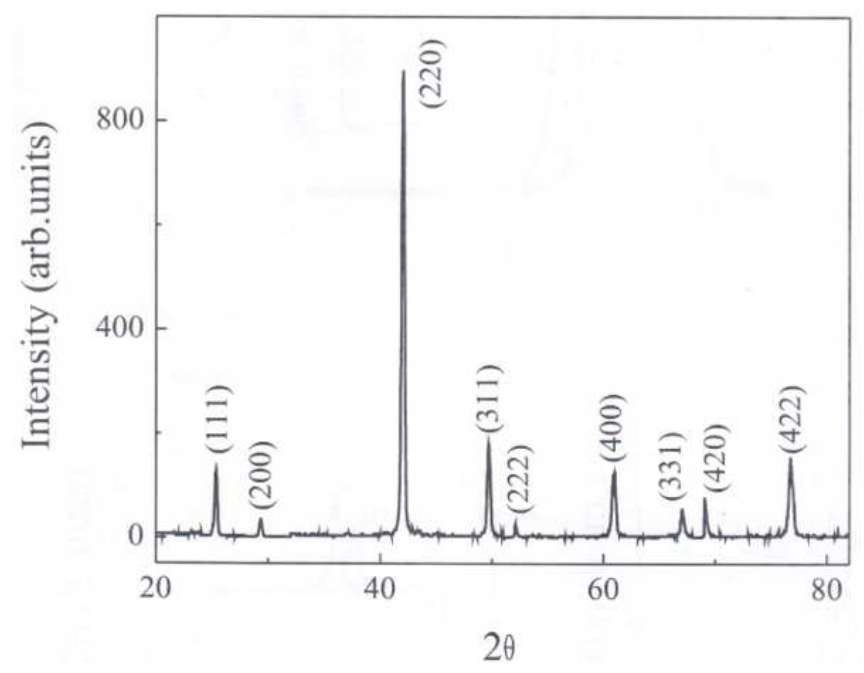

FIG. 1. XRD pattern for $\mathrm{Mn}_{2} \mathrm{Ni}_{1.6} \operatorname{In}_{0.4}$

recorded at room temperature in the angular range of $20^{\circ} \leq 2 \theta \leq 100^{\circ}$. Resistivity was measured by standard four probe technique using a closed cycle helium refrigerator in the temperature range from $10 \mathrm{~K}$ to $330 \mathrm{~K}$. Magnetization measurements were performed in the temperature interval $5 \mathrm{~K}$ - $400 \mathrm{~K}$ using a SQUID magnetometer. Here the samples were first cooled from room temperature to $5 \mathrm{~K}$ in zero applied magnetic field and the data was recorded while warming (ZFC) followed by cooling (FCC) and subsequent warming (FCW) in the same applied field of 100 Oe. For high temperature magnetization vibrating sample magnetometer was employed in the temperature range of $300 \mathrm{~K}-700 \mathrm{~K}$. Isothermal magnetization $\mathrm{M}(\mathrm{H})$ at various temperatures were recorded by ramping the field in the range $\pm 8 \mathrm{~T}$ in all five quadrants. All the $\mathrm{M}(\mathrm{H})$ loops were recorded by cooling the samples from room temperature to the desired temperature in zero applied field.

\section{RESULTS}

In Fig. 1 a typical XRD pattern of $\mathrm{Mn}_{2} \mathrm{Ni}_{1.6} \mathrm{In}_{0.4}$ is shown. All the alloys except $x=0.7$ were found to be single phase with face centered cubic structure. The (111) and (200) peaks is an indication of the highly ordered $\mathrm{Hg}_{2} \mathrm{CuTi}$ structure belonging to the $F m \overline{3} m$ space group. XRD pattern of $\mathrm{Mn}_{2} \mathrm{Ni}_{1.7} \mathrm{In}_{0.3}$ showed mixed phase with reflections belonging to austenitic cubic and martensitic tetragonal phase indicating that the martensitic transformation temperature $\left(\mathrm{T}_{M}\right)$ of this alloy to be in the vicinity of room temperature. Indeed as shown later, the transformation temperature for this alloy is $350 \mathrm{~K}$.

In Fig. 2(a -f), plots of resistivity and magnetization $(\mathrm{M}(\mathrm{T}))$ as a function of temperature are presented for $\mathrm{Mn}_{2} \mathrm{Ni}_{1+x} \operatorname{In}_{1-x}(x=0.5,0.6,0.7)$. It can be clearly seen from the nature of resistivity and magnetization curves that the two alloys $x=0.6$ and 0.7 undergo a first order magnetic transformation while $x=0.5$ has a stable ferro/ferrimagnetic metallic ground state. It may be noted that magnetic ordering in austenitic state has been termed ferrimagnetic based on band structure calculations on $\mathrm{Mn}_{2} \mathrm{NiIn}$ wherein antiferromagnetic alignment of two Mn atoms with unequal moments has been predicted $^{21,22}$. The resistivity for alloys with $x=0.6$ and 0.7 shown in Figs. 2(b) and (c) show a sharp increase and a strong hysteresis between cooling and warming data at about $230 \mathrm{~K}$ and $350 \mathrm{~K}$ respectively. This is a signature of a transformation from high temperature austenitic phase to martensitic phase. The nature and transformation temperature has been further confirmed by differential scanning calorimetric measurements as depicted in inset of Fig. 2(c). Distortion of crystal structure in the region of martensitic transformation leads to changes in band structure that results in increased scattering of conduction electrons and therefore higher resistivity. Magnetization of these two alloys measured during FCC and FCW cycles also exhibits hysteresis indicating presence of a first order transformation as can be seen in Fig. 2(e) and (f). Another interesting aspect of magnetization is the near complete destruction of magnetic order upon martensitic transformation especially in $\mathrm{Mn}_{2} \mathrm{Ni}_{1.6} \mathrm{In}_{0.4}$ (Fig. 2(e)). This effect is very similar to that observed in $\mathrm{Mn}$ rich Ni-Mn-In alloys 31 . The values of ferrimagnetic ordering temperature $\mathrm{T}_{C}$ and $\mathrm{T}_{M}$ estimated from the magnetization and resistivity data are tabulated in Table I

A closer examination of magnetization curves in $\mathrm{Mn}_{2} \mathrm{Ni}_{1.6} \mathrm{In}_{0.4}$ reveals that below $125 \mathrm{~K}$, the magnetization starts increasing with decreasing temperature which is suggestive of another magnetic transition, $\mathrm{T}_{C}^{M}$ typically referred to as magnetic ordering temperature of martensitic phase. Interestingly, below $\mathrm{T}_{C}^{M}$, a splitting of the ZFC and the FC curves is observed which can be ascribed to the presence of competing antiferromagnetic interactions $32-34$.

From the above results it seems that the martensitic transformation in $\mathrm{Mn}_{2} \mathrm{Ni}_{(1+x)} \operatorname{In}_{(1-x)}$ alloys occurs only in alloys with $x \geq 0.6$. This corresponds to an average valence electron per atom (e/a ratio) of 7.8. Interestingly, even in $\mathrm{Ni}_{2} \mathrm{Mn}_{(1+x)} \operatorname{In}_{(1-x)}$ alloys , martensitic transformation occurs in alloy composition with e/a ratio $\geq 7.831$. In order to investigate the range of e/a ratio over which Mn-Ni-In alloys undergo martensitic transformation, the compositions were fine tuned by varying $\mathrm{Mn}$ to $\mathrm{Ni}$ ratio in $\mathrm{Mn}_{2} \mathrm{Ni}_{1.6} \mathrm{In}_{0.4}$ resulting in alloys of the type $\mathrm{Mn}_{(2+y)} \mathrm{Ni}_{(1.6-y)} \operatorname{In}_{0.4}(\mathrm{y}=-0.08,-0.04,0.04,0.08)$.

Results of temperature dependence of resistivity recorded during warming and cooling cycles and magnetization recorded during ZFC, FCC and FCW cycles for $\mathrm{Ni}$ rich compositions $\mathrm{Mn}_{1.92} \mathrm{Ni}_{1.68} \mathrm{In}_{0.4}$ and $\mathrm{Mn}_{1.96} \mathrm{Ni}_{1.64} \mathrm{In}_{0.4}$ are presented in Fig. 3(a)-(b) and Fig. 3(c)-(d) respectively. Both the alloys are martensitic with $\mathrm{T}_{M} 270 \mathrm{~K}$ and $245 \mathrm{~K}$ respectively. The behavior of magnetization is also very similar to that of $\mathrm{Mn}_{2} \mathrm{Ni}_{1.6} \mathrm{In}_{0.4}$. It can also be noticed that with the in- 




FIG. 2. Resistivity plots for (a) $\mathrm{Mn}_{2} \mathrm{Ni}_{1.5} \operatorname{In}_{0.5}$ (b) $\mathrm{Mn}_{2} \mathrm{Ni}_{1.6} \mathrm{In}_{0.4}$ (c) $\mathrm{Mn}_{2} \mathrm{Ni}_{1.7} \operatorname{In}_{0.3}$ and Magnetization plots for (d) $\mathrm{Mn}_{2} \mathrm{Ni}_{1.5} \mathrm{In}_{0.5}$ (e) $\mathrm{Mn}_{2} \mathrm{Ni}_{1.6} \operatorname{In}_{0.4}$ (f) $\mathrm{Mn}_{2} \mathrm{Ni}_{1.7} \operatorname{In}_{0.3}$

TABLE I. Values of e/a, $\mathrm{T}_{C}, \quad \mathrm{~T}_{M}$ and $\mathrm{T}_{C}^{M}$ for $\mathrm{Mn}_{2} \mathrm{Ni}_{(1+x)} \operatorname{In}_{(1-x)}$ and $\mathrm{Mn}_{(2-y)} \mathrm{Ni}_{(1.6+y)} \operatorname{In}_{0.4}$ alloys

\begin{tabular}{|c|c|c|c|c|}
\hline Alloy & e/a ratio & $\mathrm{T}_{M}$ & $\mathrm{~T}_{C}$ & $\mathrm{~T}_{C}^{M}$ \\
\hline $\mathrm{Mn}_{2} \mathrm{Ni}_{1.7} \mathrm{In}_{0.3}$ & 7.975 & $350 \mathrm{~K}$ & $620 \mathrm{~K}$ & - \\
$\mathrm{Mn}_{1.92} \mathrm{Ni}_{1.68} \mathrm{In}_{0.4}$ & 7.86 & $270 \mathrm{~K}$ & $327 \mathrm{~K}$ & $135 \mathrm{~K}$ \\
$\mathrm{Mn}_{1.96} \mathrm{Ni}_{1.64} \mathrm{In}_{0.4}$ & 7.83 & $245 \mathrm{~K}$ & $326 \mathrm{~K}$ & $125 \mathrm{~K}$ \\
$\mathrm{Mn}_{2} \mathrm{Ni}_{1.6} \mathrm{In}_{0.4}$ & 7.8 & $232 \mathrm{~K}$ & $344 \mathrm{~K}$ & $122 \mathrm{~K}$ \\
$\mathrm{Mn}_{2.04} \mathrm{Ni}_{1.56} \mathrm{In}_{0.4}$ & 7.77 & - & $340 \mathrm{~K}$ & - \\
$\mathrm{Mn}_{2.08} \mathrm{Ni}_{1.52} \mathrm{In}_{0.4}$ & 7.74 & - & $362 \mathrm{~K}$ & - \\
$\mathrm{Mn}_{2} \mathrm{Ni}_{1.5} \mathrm{In}_{0.5}$ & 7.625 & - & $350 \mathrm{~K}$ & - \\
\hline
\end{tabular}

crease in $\mathrm{Ni}$ concentration the martensitic transformation temperature increases. Whereas the Mn rich compositions, $\mathrm{Mn}_{2.04} \mathrm{Ni}_{1.56} \mathrm{In}_{0.4}$ and $\mathrm{Mn}_{2.08} \mathrm{Ni}_{1.52} \mathrm{In}_{0.4}$ exhibit ferrimagnetic metallic behavior (Fig. 4) similar to $\mathrm{Mn}_{2} \mathrm{Ni}_{1.5} \mathrm{In}_{0.5}$. The magnetic and martensitic transformation temperatures for all the alloys are listed in Table I. It can be clearly seen that while magnetic ordering temperature decreases (except $\mathrm{Mn}_{2} \mathrm{Ni}_{1.7} \mathrm{In}_{0.3}$ ), martensitic transformation temperature increases systematically with (e/a) ratio.

The nature of magnetization in $\mathrm{Mn}_{1.92} \mathrm{Ni}_{1.68} \mathrm{In}_{0.4}$ (Fig](c)) and $\mathrm{Mn}_{1.96} \mathrm{Ni}_{1.64} \mathrm{In}_{0.4}$ (Fig. 3(d)), is also very similar to that of $\mathrm{Mn}_{2} \mathrm{Ni}_{1.6} \mathrm{In}_{0.4}$. In the martensitic phase, a splitting of the ZFC and FC curves is observed below $\mathrm{T}_{C}^{M} \sim 150 \mathrm{~K}$ and $100 \mathrm{~K}$ respectively, which again suggests the presence of competing magnetic interactions.

The austenitic state in these alloys is characterized by ferrimagnetic ordering due to antiparallel alignment of the two unequal Mn moments ${ }^{21,22}$. However, the nature magnetic ordering in martensitic phase is not clear. It has been argued that martensitic transformation in such Mn rich alloys leads to change from a ferrimag-

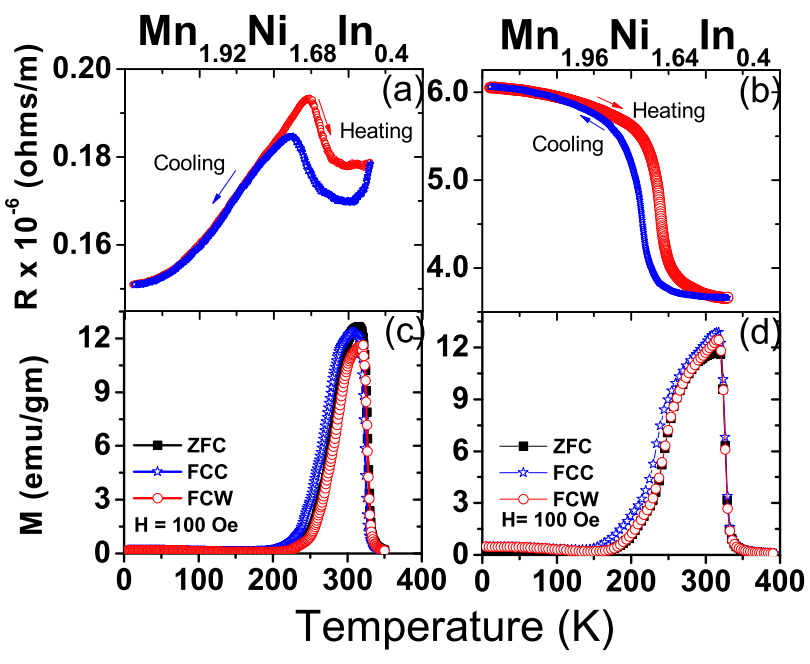

FIG. 3. Resistivity plots for (a) $\mathrm{Mn}_{1.92} \mathrm{Ni}_{1.68} \mathrm{In}_{0.4}$ (b) $\mathrm{Mn}_{1.96} \mathrm{Ni}_{1.64} \mathrm{In}_{0.4}$ and Magnetization plots for (c) $\mathrm{Mn}_{1.92} \mathrm{Ni}_{1.68} \mathrm{In}_{0.4}$ (d) $\mathrm{Mn}_{1.96} \mathrm{Ni}_{1.64} \mathrm{In}_{0.4}$

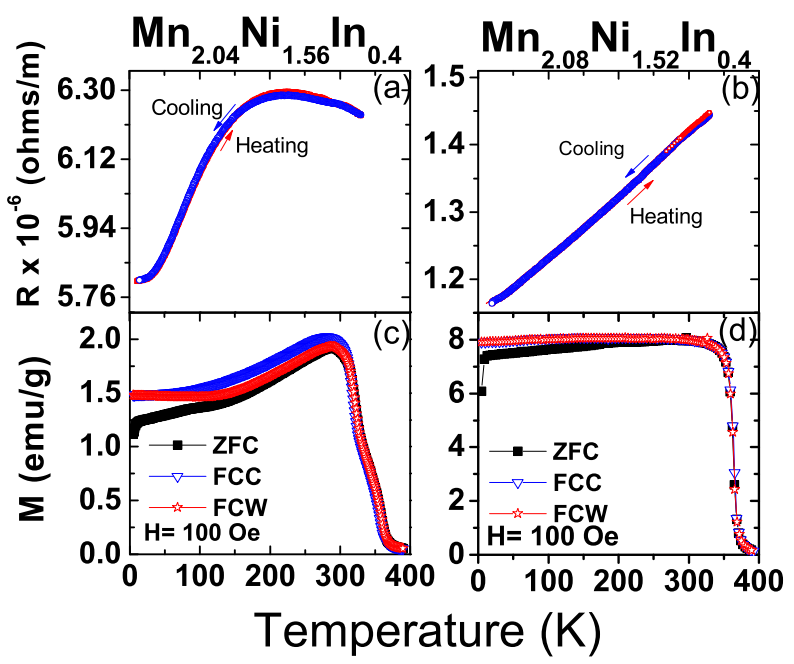

FIG. 4. Resistivity plots for (a) $\mathrm{Mn}_{2.04} \mathrm{Ni}_{1.56} \mathrm{In}_{0.4}$ and (b) $\mathrm{Mn}_{2.08} \mathrm{Ni}_{1.52} \mathrm{In}_{0.4}$ and Magnetization plots for (c) $\mathrm{Mn}_{2.04} \mathrm{Ni}_{1.56} \mathrm{In}_{0.4}$ and (d) $\mathrm{Mn}_{2.08} \mathrm{Ni}_{1.52} \mathrm{In}_{0.4}$

netic to an antiferromagnetic state with competing magnetic interactions ${ }^{30}$. In the alloy compositions studied here, a near destruction of magnetic order is observed upon martensitic transformation followed by some kind of magnetic reordering at $\mathrm{T}_{C}^{M}$. In order to understand in detail, the nature of magnetic interactions in the martensitic phase, isothermal magnetization $(\mathrm{M}(\mathrm{H}))$ measurements have been performed at several temperatures below $\mathrm{T}_{M}$ of $\mathrm{Mn}_{2} \mathrm{Ni}_{1.6} \mathrm{In}_{0.4}$ and $\mathrm{Mn}_{1.96} \mathrm{Ni}_{1.64} \mathrm{In}_{0.4}$ and compared them with structurally stable $\mathrm{Mn}_{2.04} \mathrm{Ni}_{1.56} \mathrm{In}_{0.4}$ alloy.

The $\mathrm{M}(\mathrm{H})$ data for $\mathrm{Mn}_{2} \mathrm{Ni}_{1.6} \operatorname{In}_{0.4}$ at various temperatures from $5 \mathrm{~K}$ to $300 \mathrm{~K}$ is presented in Fig. 5. The $\mathrm{M}(\mathrm{H})$ curves at $300 \mathrm{~K}$ and $250 \mathrm{~K}$ are in the ferrimagnetic 


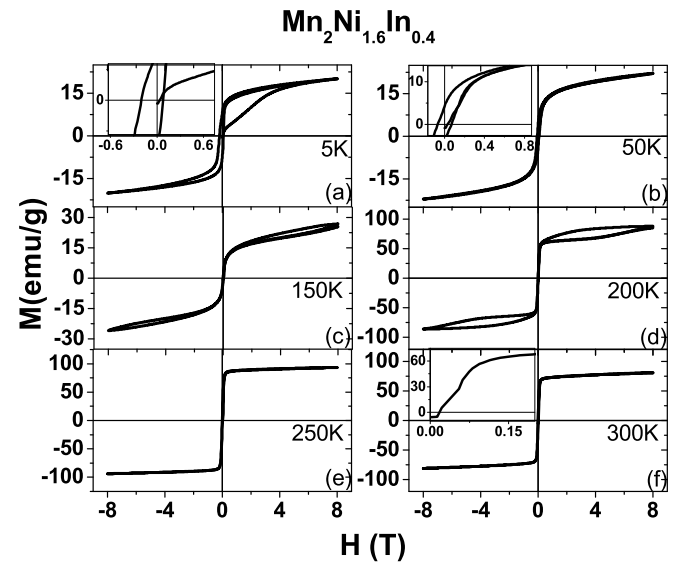

FIG. 5. $\mathrm{MH}$ plot for $\mathrm{Mn}_{2} \mathrm{Ni}_{1.6} \mathrm{In}_{0.4}$ at (a) $5 \mathrm{~K}$, (b) $50 \mathrm{~K}$, (c) $150 \mathrm{~K}$, (d) $200 \mathrm{~K}$, (e) $250 \mathrm{~K}$ and (f) $300 \mathrm{~K}$

austenitic state. A metamagnetic transition at very low values of magnetic field and the non-saturating magnetic moments are characteristics of these hysteresis loops (See inset of Fig. 5(f)) . These characteristics signify the presence of a weak antiferromagnetic interactions ${ }^{35}$. It may be noted that $\mathrm{Ni}$ too has a magnetic moment, though much smaller than $\mathrm{Mn}$, can interact with the ordered moment of $\mathrm{Mn}$ in presence of magnetic field giving rise to a metamagnetic transition. Furthermore, there are preferential site occupancies of various atoms forming Heusler compositions ${ }^{16}$. Accordingly, in $\mathrm{Mn}_{2} \mathrm{Ni}_{1.6} \mathrm{In}_{0.4}$, it is possible that Ni may prefer the $\mathrm{X}$ sites forcing Mn to occupy the In (Z) sites. This will lead to new magnetic correlations resulting in complex magnetic order.

In the martensitic state the competing interactions are further amplified as can be seen from the $\mathrm{M}(\mathrm{H})$ loop at $200 \mathrm{~K}$ (Fig. 5). The hysteresis loop is similar to that at $250 \mathrm{~K}$ curve but with lobular structures in the positive and negative applied field regions extending over the entire range of magnetic field. This is due to non reversibility of magnetic moments arising from formation of new martensitic variants in presence of magnetic field. These lobular structure in the $\mathrm{M}(\mathrm{H})$ loops disappear below $150 \mathrm{~K}$ or for the loops recorded below $\mathrm{T}_{C}^{M}$. The $\mathrm{M}(\mathrm{H})$ loops recorded at $\mathrm{T}<100 \mathrm{~K}$ exhibit finite coercivity indicating a build up of ferromagnetic interactions. Such ferromagnetic nanodomains have also been seen in $\mathrm{Mn}_{2} \mathrm{NiGa}$ and are ascribed to antisite disorder ${ }^{29}$. The $\mathrm{M}(\mathrm{H})$ loop at $50 \mathrm{~K}$ has a coercivity of around 695 Oe and it increases with decreasing temperature. The hysteresis loops, though recorded under zero field cooling protocol, exhibit exchange bias effect which have been recently demonstrated to be characteristic of ferrimagnetic order. This effect can be readily seen at $5 \mathrm{~K}$ and the calculated exchange bias field $\mathrm{H}_{E B}$ is -639 Oe while the coercivity $\mathrm{H}_{c}$ is $\sim 1400$ Oe. It can also be seen that the virgin magnetization curve lies outside the hysteresis envelope indicating presence of more than one magnetic phases below $\mathrm{T}_{C}^{M}$.

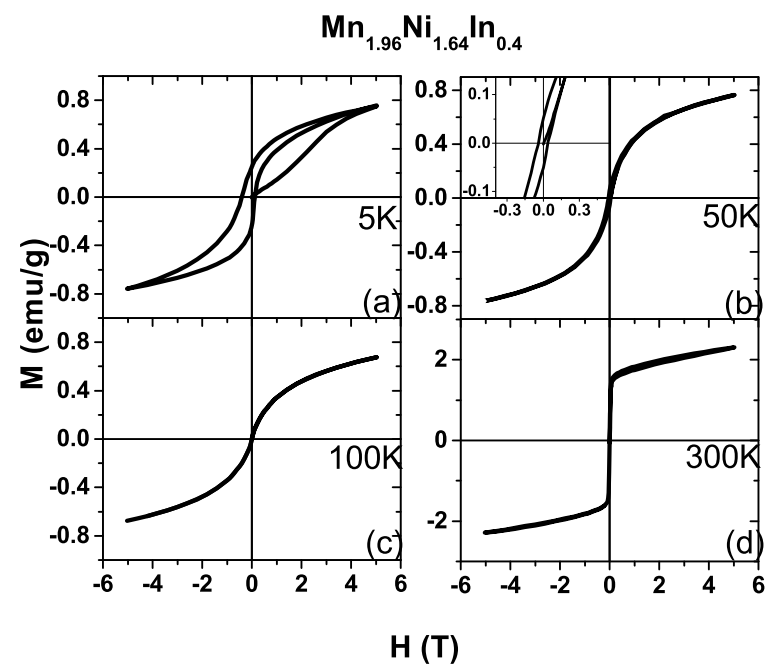

FIG. 6. $\mathrm{MH}$ data for $\mathrm{Mn}_{1.96} \mathrm{Ni}_{1.64} \mathrm{In}_{0.4}$ Figs(a)to(d) are the plots for temperatures (a) $5 \mathrm{~K}$,(b) $50 \mathrm{~K}$,(c) $100 \mathrm{~K}$ and (d) $300 \mathrm{~K}$ respectively

Nearly similar behavior of $\mathrm{M}(\mathrm{H})$ loops is noticed in case of $\mathrm{Mn}_{1.96} \mathrm{Ni}_{1.64} \mathrm{In}_{0.4}$ as can be seen from Fig. 6] Here too, the zero field cooled hysteresis loops exhibit exchange bias effect. The estimated values of coercive field and exchange bias field are $\mathrm{H}_{c}=2784$ Oe and $\mathrm{H}_{E B}=1329$ Oe respectively. These values are much higher than those calculated for $\mathrm{Mn}_{2} \mathrm{Ni}_{1.6} \mathrm{In}_{0.4}$. This is again an interesting observation because it implies that with increase in $\mathrm{Ni}$ concentration both, ferromagnetic and antiferromagnetic interaction strengthen. This is possible only if increase in $\mathrm{Ni}$ concentration is in some way responsible for more antisite disorder.

In Fig. 7. $\mathrm{M}(\mathrm{H})$ loops for $\mathrm{Mn}_{2.04} \mathrm{Ni}_{1.56} \mathrm{In}_{0.4}$ are presented. It is interesting to see that a slight decrease in $\mathrm{Ni}$ concentration not only results a stable austenitic structure. All the $\mathrm{M}(\mathrm{H})$ loops recorded from $5 \mathrm{~K}$ to $300 \mathrm{~K}$ exhibit similar behavior with no saturation of magnetic moment up to $\mathrm{H}=7 \mathrm{~T}$. However, the magnetic moment value recorded is quite low $\sim 32 \mathrm{emu} / \mathrm{gm}$ and is nearly independent of temperature.

\section{DISCUSSION}

$\mathrm{Mn}_{2} \mathrm{NiIn}$ is a Heusler alloy wherein the $\mathrm{X}$ sites are shared equally by $\mathrm{Ni}$ and $\mathrm{Mn}$, the $\mathrm{Y}$ sites are occupied entirely by $\mathrm{Mn}$ and the $\mathrm{Z}$ sites by In. Increasing Ni content at the expense of In concentration leads to martensitic alloys. The martensitic transformation occurs at nearly the same value of e/a as in case of $\mathrm{Mn}$ rich $\mathrm{Ni}_{2} \mathrm{MnIn}$ type alloys. Another interesting aspect of this study is the critical dependence of martensitic and magnetic properties on Ni concentration. Though all the alloys exhibit ferrimagnetic ordering in the austenitic state, the martensitic state is characterized with the presence of ferromagnetic and antiferromagnetic interactions. Both these interac- 


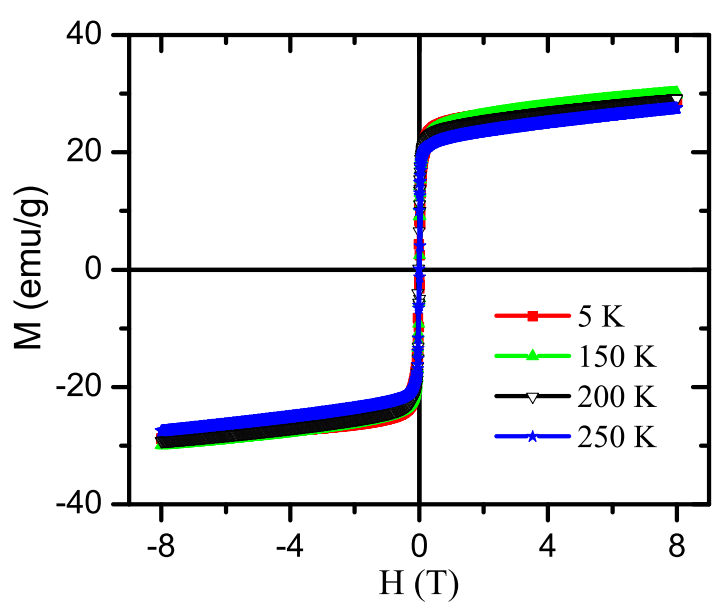

FIG. 7. $\mathrm{MH}$ data for $\mathrm{Mn}_{2.04} \mathrm{Ni}_{1.56} \mathrm{In}_{0.4}$

tions seem to dominate with increase in Ni concentration.

From the individual site preferences of transition metal ions, it is expected that $\mathrm{Ni}$ will prefer $\mathrm{X}$ sites forcing $\mathrm{Mn}$ in occupying the $\mathrm{Z}$ sites. Therefore an increase in $\mathrm{Ni}$ concentration will lead to more Mn occupying $\mathrm{Z}$ sites resulting in an antisite disorder. Such an antisite disorder is known to induce competing magnetic interactions result in a complex magnetic ground state 29,30 . Indeed, the martensitic state of these alloys exhibit strongly competing magnetic interactions. In order to determine if site preferences of various atoms is responsible for the observed magnetic ground state, we compare the values of magnetic moment at $300 \mathrm{~K}$ in $\mathrm{Mn}_{2} \mathrm{Ni}_{1.6} \mathrm{In}_{0.4}$ and its $\mathrm{Ni}$ rich $(y=0.04$ and 0.08$)$ and $\mathrm{Ni}$ deficient $(y=-0.04$ and -0.08 ) counterparts. Though both Ni deficient and Ni deficient alloys have similar ferrimagnetic ordering temperature, a comparison of $\mathrm{M}(\mathrm{H})$ loops at $300 \mathrm{~K}$ shows that magnetic moment measured at $7 \mathrm{~T}$ in $\mathrm{Mn}_{2.04} \mathrm{Ni}_{1.56} \mathrm{In}_{0.4}$ $(\sim 32 \mathrm{emu} / \mathrm{g})$ is less than half of that in $\mathrm{Mn}_{2} \mathrm{Ni}_{1.6} \mathrm{In}_{0.4}$
( $\sim 80 \mathrm{emu} / \mathrm{g})$. Such a large decrease in the value of magnetic moment can only be accounted for by considering a strong antiferromagnetic component coming from a sizable fraction of $\mathrm{Mn}$ occupying $\mathrm{Z}$ sites. The sizable shift of $\mathrm{Mn}$ atoms at $\mathrm{Z}$ sites reduces its occupancy of $\mathrm{X}$ sites. Such a site occupancy disorder results in increasing the dominance of both, ferromagnetic interaction between $\mathrm{Mn}$ atoms in $\mathrm{Y}$ sublattice and antiferromagnetic interactions between $\mathrm{Mn}(\mathrm{Y})$ and $\mathrm{Mn}(\mathrm{Z})$ atoms. Such a competition then gives rise to the observed strong exchange bias effect.

\section{CONCLUSION}

In summary, we have presented a systematic study of the martensitic and magnetic interactions in Heusler alloys of the type $\mathrm{Mn}_{2} \mathrm{Ni}_{(1+x)} \operatorname{In}_{(1-x)}$ and $\mathrm{Mn}_{(2-y)} \mathrm{Ni}_{(1.6+y)} \mathrm{In}_{0.4}$. Martensitic instability can be induced by increasing Ni content at the expense of In. Such a increase in $\mathrm{Ni}$ content results in a site occupancy disorder due to preferential occupation of $\mathrm{X}$ sites by Ni atoms forcing $\mathrm{Mn}$ atoms to occupy the $\mathrm{Z}$ sites. This results in a transformation of magnetic ground state from ferrimagnetic to one dominated by presence of ferromagnetic $\mathrm{Mn}(\mathrm{Y})-\mathrm{Mn}(\mathrm{Y})$ and antiferromagnetic $\mathrm{Mn}(\mathrm{Y})-\mathrm{Mn}(\mathrm{Z})$ interactions. Such a transition is responsible for observation of properties like exchange bias effect in zero field cooled state in these Mn rich martensitic alloys.

\section{ACKNOWLEDGEMENTS}

Authors would like to acknowledge the financial assistance from Council for Scientific and Industrial Research, New Delhi under the project 09/EMR-II/1188. Help of Devendra Buddhikot and Ganesh Jangam in magnetization measurements is gratefully acknowledged.
* corresponding author: krp@unigoa.ac.in

${ }^{1}$ K. Ullakko, J. K. Huang,C. Kantner, R. C. O'Handley and V. V. Kokorin, Appl. Phys. Lett. 691966 (1996).

2 A. Planes, L. Mañosa and A. Saxena Magnetism and Structure in Functional materials (Material Science Series vol. 79 (Berlin: Springer) (2005).

3 A. N. Vasil'ev, V.D. Buchel'nikov, T. Takagi, V. V. Khovailo, E. I. Estrin, Physics Uspekhi 46, 559 (2003).

4 T. Krenke, E. Duman, M. Acet, E.F. Wassermann, X. Moya, Ll. Manosa, A. Planes, E. Suard, and B. Ouladdiaf, Phys. Rev. B 75104414 (2007).

5 A. Planes, L. Mañosa, and M. Acet, J. Phys. Condens. Matter 21,233201 (2009).

6 P. J. Shamberger and F. S. Ohuchi, Phys. Rev. B 79, 144407 (2009).

7 P. A. Bhobe, K. R. Priolkar and A. K. Nigam, Appl. Phys. Lett. 91, 242503 (2007).
${ }^{8}$ R. Kainuma, Y. Imano,W. Ito, Y. Sutou, H. Morito, S. Okamoto, O. Kitakami, K. Oikawa, A. Fujita, T. Kanomata and K. Ishida, Nature(London), 439957 (2006).

9 K. Koyama, K. Watanabe, T. Kaomata, R. Kainuma, K. Oikawa and K. Ishida, Appl. Phys. lett., 88132506 (2006).

10 A. K. Pathak, M. Khan, B. R. Gautam, S. Stadler, I. Dubenko and N. Ali, J. Magn. Magn. Mater 321, 963 (2009).

11 P. A. Bhobe, K. R. Priolkar and A. K. Nigam, J. Phys. D: Appl. Phys. 41, 235006 (2008).

12 K. Koyama, H. Okada, K. Watanabe, T. Kanomata, R. Kainuma, W. Ito, K. Oikawa, and K. Ishida, Appl. Phys. Lett. 89, 182510 (2006).

13 X. Zhou, H. Kunkel, G. Williams, S. Zhang, and X. Desheng, J. Magn. Magn. Mater. 305, 372 (2006). 
14 Z. Li, C. Jing, J. Chen, S. Yuan, S. Cao, and J. Zhang, Appl. Phys. Lett. 91, 112505 (2007).

15 G. D. Liu, J. L. Chen, Z. H. Liu, X. F. Dai, G. H. Wu, B. Zhang, and X. X. Zhang, Appl. Phys. Lett. 87, 262504 (2005).

16 G. D. Liu, X. F. Dai, S. Y. Yu, Z. Y. Zhu, J. L. Chen and G. H. Wu, H. Zhu, J. Q. Xiao, Phys. Rev B 74, 054435 (2006).

17 G. D. Liu, J. L. Chen, Z. H. Liu, X. F. Dai, G. H. Hu, B. Zang and X. X. Wang, Appl. Phys. Lett. 87262504 (2003).

18 S. R. Barman, S. Banik, A. K. Shukla, C. Kamal and A. Chakrabarti, Euro. Phys. Lett, 8057002 (2007).

19 S. R. Barman and A. Chakrabarti, Phys. Rev. B 77176401 (2008).

20 Souvik Paul and S. Ghosh, J Phys: Condensed matter 23 206003 (2011).

21 A. Chakrabarti and S. R. Barman, Appl. Phys. Lett. 94 161908 (2009).

${ }^{22}$ H. Luo, G. Liu, F. Meng, S. Li, W. Zhu, G. Wu, X. Zhu and C. Jiang, Physica B 4053092 (2010).

${ }^{23}$ L. Ma, S. Q. Wang, Y. Z. Li, C. M. Zhen, D. L. Hou, W. H. Wang, J. L. Chen and G. H. Wu, J. Appl. Phys. 112 082902 (2012).

24 J. L. Sánchez Llamazares, B. Hernando, V. M. Prida, C. García, J. González, R. Varga and C. A. Ross J. Appl. Phys. 105, 07A945 (2009).

25 J. Barth, B. Balke, G. H. Fecher, H. Stryhanyuk, A. Gloskovskii, S. Naghavi and C. Felser, J. Phys. D:Appl.
Phys. 42, 185401 (2009).

26 D. N. Lobo, K. R. Priolkar, P. A. Bhobe, D. Krishnamurthy, and S. Emura, Appl. Phys. Lett. 96, 232508 (2010).

27 K. R. Priolkar, D. N. Lobo, P. A. Bhobe, S. Emura and A. K. Nigam, Euro. Phys. Lett. 94, 38006 (2011).

${ }^{28}$ K. R. Priolkar, P. A. Bhobe, D. N. Lobo, S. W. D'Souza, S. R. Barman, A. Chakrabarti and S. Emura, Phys. Rev. B. 87144412 (2013)

29 S. Singh, R. Rawat, S. E. Muthu, S. W. D'Souza, E. Suard, A. Senyshyn, S. Banik, P. Rajput, S. Bhardwaj, A. M. Awasthi, R. Rajan, S. Arumugam, D. L. Schlagel, T. A. Lograsso, A. Chakrabarti and S. R. Barman, Phys. Rev. Lett 109, 246601 (2012).

30 A. K. Nayak, M. Nicklas, S. Chadov, C. Shekhar, Y. Skourski, J. Winterlik and C. Felser, Phys. Rev. Lett 110, 127204 (2013).

31 T. Krenke, M. Acet, E. F. Wassermann, X. Moya, L. Mañosa and A. Planes, Phys. Rev B 73174413 (2006).

32 H. C. Xuan, Q. Q. Cao, C. L. Zhang, S.C. Ma, S.Y. Chen, D.H.Wang and Y.W. Diu. Appl Phys. lett. 96, 202502 (2010).

33 J .L. Sánchez Liamazares, B. Hernando, J. J. Suñol, C. Garcia and C.A. Ross J. Appl. Phys. 107, 09 A956 (2010).

34 S. Y. Chu, A. Cramb, M. De Graef, D. Laughlin, and M. E. McHenry, J. Appl. Phys. 87, 5777 (2000).

35 N. Ali and X. Zhang, J. Phys.: Condens. Matter 4, L351 (1992). 